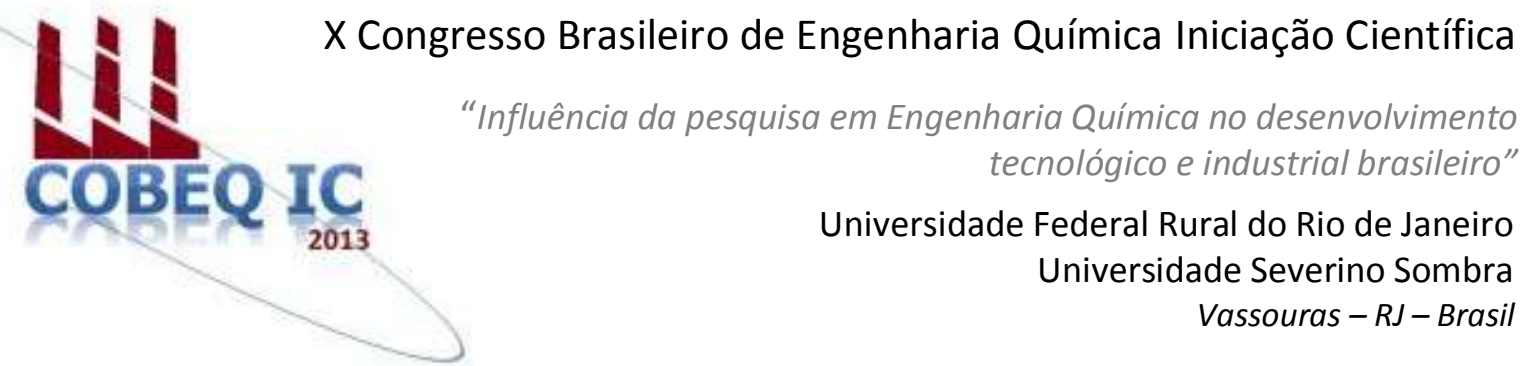

\title{
LEVANTAMENTO DO TEMPO DE EXPOSIÇÃO DE RADIAÇÃO UV DISPONÍVEL EM NATAL/RN
}

\author{
B. S. ROCHA ${ }^{1}$, I. M. V. ROCHA ${ }^{1}$, K. H. N. OLIVEIRA ${ }^{1}$ E M.A.S.B. SOUSA ${ }^{2}$ \\ ${ }^{1}$ Bolsista de Iniciação Científica - DEQ/UFRN ${ }^{2}$ Docente - DEQ/UFRN \\ Departamento de Engenharia Química - Centro de Tecnologia - UFRN \\ Campus Universitário - Lagoa Nova - Natal, RN - CEP 59120-140 \\ email: magnelica@eq.ufrn.br
}

\begin{abstract}
RESUMO - O uso da radiação ultravioleta (UV) é uma eficaz forma de tratamento da água, uma vez que inativa os microorganismos e não gera subprodutos cancerígenos, diferentemente da cloração. Um ambiente como Natal, onde a radiação UV incide abundantemente, é ideal para desenvolver pesquisas nessa área. Para tanto, o presente trabalho consistiu na aquisição de dados da base do Instituto Nacional de Pesquisa Espaciais (INPE) a respeito da radiação UV em Natal entre 2009 e 2012, em especial de maio a julho (períodos chuvosos na região), seguido da tabulação dos dados obtidos para o horário das $5 \mathrm{~h}$ até as $17 \mathrm{~h}$. O valor máximo foi $1000 \mathrm{~W} / \mathrm{m}^{2}$ e o mínimo obtido (coincidindo com os nublados e com chuva) foi de $250 \mathrm{~W} / \mathrm{m}^{2}$, demonstrando que mesmo na época menos ensolarada a desinfecção é possível.
\end{abstract}

Palavras chave: radiação, desinfecção, potencial solar.

\section{INTRODUÇÃO}

Um dos principais problemas que afligem o homem contemporâneo trata do acesso à água: sua escassez atinge um semnúmero de pessoas em todo o planeta e, mesmo quando se encontra disponível, sua má qualidade a impede de ser consumida. Para se tornar potável, a água passa por processos de desinfecção que objetivam eliminar ou inativar os microorganismos nela presentes e, assim, evitar as doenças causadas pelos mesmos.

O método de desinfecção mais comum de tratamento de águas envolve a utilização de cloro, que tem como principal desvantagem a formação de subprodutos potencialmente cancerígenos. As alternativas a este costumam apresentar gastos elevados. Neste contexto, a desinfecção via radiação solar ultravioleta (UV) apresenta-se como uma opção menos nociva e mais barata de tratamento, sendo uma excelente saída para a população mais carente, possibilitando-lhe dispor de água desinfetada a baixos custos.

A ação da radiação UV na inativação de microorganismos se dá por alterações em seu material genético. $\mathrm{O}$ ácido desoxirribonucleico (DNA) é responsável pela formação do ácido ribonucleico (RNA), que, por sua vez, coordena a síntese proteica, indispensável ao metabolismo celular. O DNA é formado por estruturas denominadas nucleotídeos, constituídas por ácido fosfórico, desoxirribose e alguma das quatro bases 
(adenina, timina, guanina e citosina) que se ligam em dois pares (adenina com timina, guanina com citosina), mantendo a cadeia dupla unida. Quando a bactéria é exposta à radiação UV, a mesma é absorvida e provoca rompimento das ligações entre as bases e a posterior formação de ligação entre nucleotídeos adjacentes e formando dímeros que, em quantidade suficiente, impede a duplicação de DNA e, consequentemente, compromete todo o metabolismo bacteriano.

Natal, conhecida com a Cidade do Sol, é um local apropriado para pesquisas relacionadas à aplicação desse método, devido à recorrência de dias ensolarados e, consequentemente, ao elevado nível de radiação ultravioleta incidente.

\section{OBJETIVOS}

Realizar o levantamento e análise dos índices anuais de radiação UV na cidade de Natal/RN entre 2009 a 2012;

Identificar o tempo de exposição mínimo necessário para realização de desinfecção satisfatória;

Verificar a aplicabilidade da desinfecção solar na estação chuvosa da cidade, período compreendido entre julho e agosto, período mais crítico para o uso da radiação.

\section{METODOLOGIA}

Foi realizada a tabulação de dados utilizando o sítio do Instituto Nacional de Pesquisas Espaciais (INPE), onde foram obtidos os valores de Radiação Solar, Precipitação, Índice de Radiação Ultravioleta (UV) e Velocidade dos Ventos para todos os dias dos últimos cinco anos na cidade de Natal/RN.

Os dados foram analisados entre as $5 \mathrm{~h}$ e 17h, e, uma vez completado o mês corrente, foi feita a média aritmética dos valores para melhor visualização de comportamento durante o ano.

Por fim, os valores de radiação solar média foram dispostos em gráficos de barras, utilizando o programa Microsoft Excel.

\section{RESULTADOS}

Os gráficos abaixo mostram os valores de radiação solar média para a cidade de Natal entre os anos de 2009 e 2012.

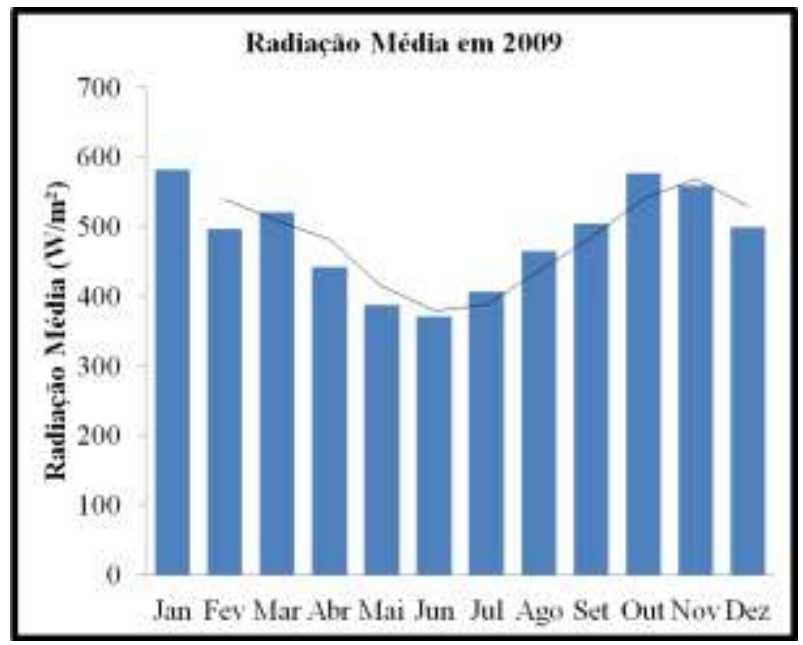

Figura 01 - Radiação média mensal em Natal no ano de 2009.

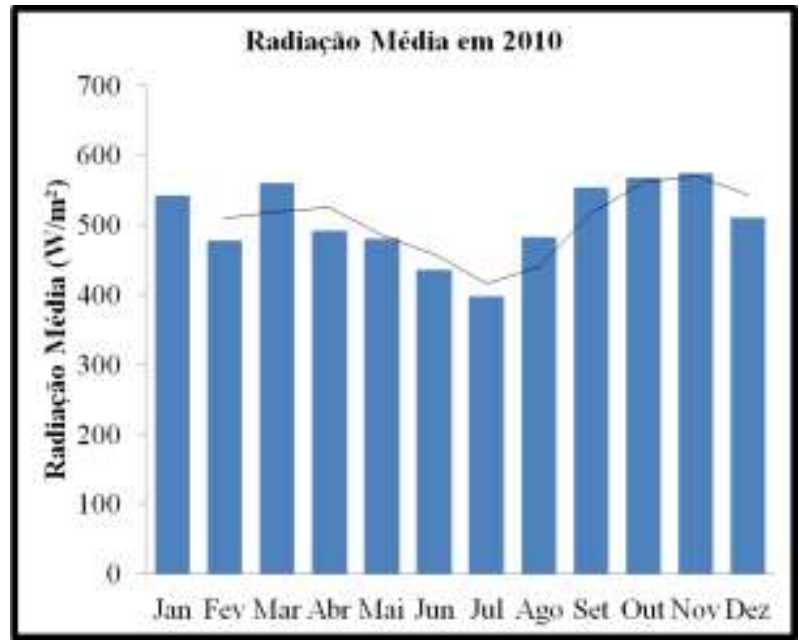

Figura 02 - Radiação média mensal em Natal no ano de 2010. 


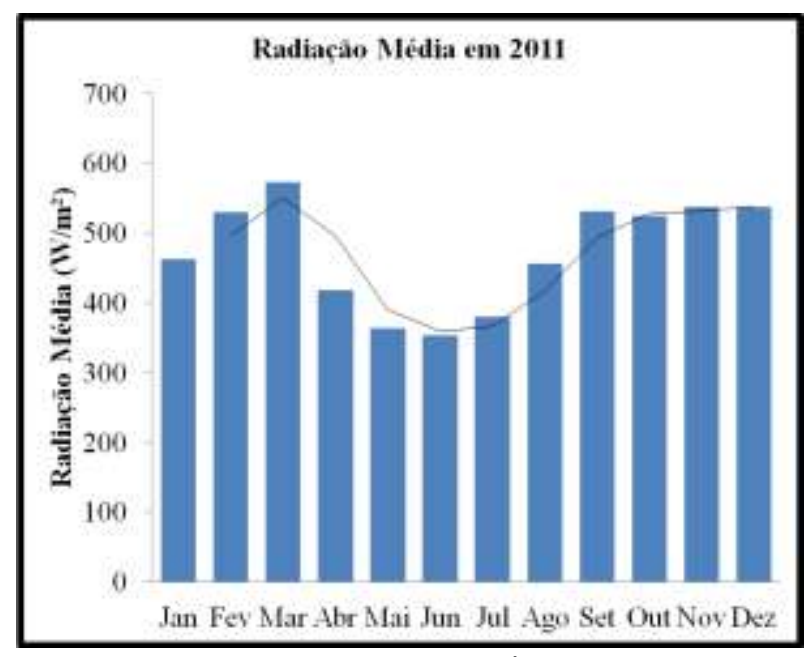

Figura 03 - Radiação média mensal em Natal no ano de 2011.

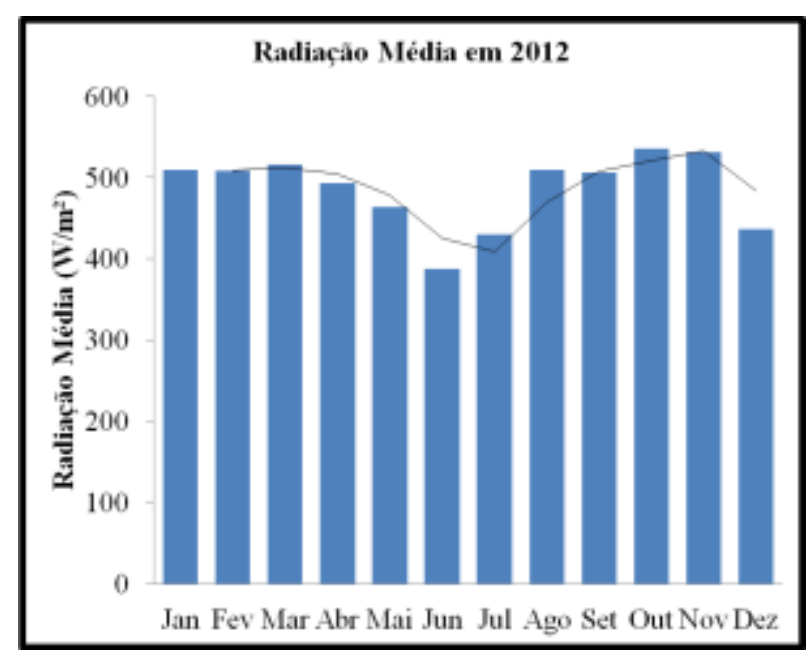

Figura 04 - Radiação média mensal em Natal no ano de 2012.

\section{DISCUSSÕES}

Verifica-se uma diminuição significativa nos valores de radiação para os meses de Maio, Junho e Julho para os anos observados devido ao fato de que para esses meses ocorre o período ou estação chuvosa na cidade. Isso implica em uma possível interferência no rendimento da desinfecção por radiação UV.

Além disso, os resultados obtidos no sítio do INPE mostram valores de radiação entre $250 \mathrm{~W} / \mathrm{m}^{2}$ e $1000 \mathrm{~W} / \mathrm{m}^{2}$, cujos valores mínimos coincidem com os dias em que houve precipitações pluviométricas.

\section{CONCLUSÕES}

A cidade de Natal possui um grande potencial solar para aplicação na desinfecção UV, método esse que na literatura, além de ter um baixo custo de execução, tem demonstrado ser um grande aliado à regiões subdesenvolvidas, onde a carência de água potável é um problema recorrente.

O próximo passo é realizar testes em escala laboratorial para confirmar a eficácia da desinfecção nos meses chuvosos, que apresentam os menores índices de radiação. Os pontos a se observar serão: tempo de exposição do sistema, vazão de água no equipamento, e se haverá remoção total ou redução dos coliformes.

\section{REFERÊNCIAS}

BURCH, J. D., THOMAS, K. E. Water disinfection for developing countries and potential for solar thermal pasteurization. Elsevier, USA, Solar Energy Vol. 64, p. 87-97. 1998.

MARQUES, A. R. et al. Efficiency of PET reactors in solar water disinfection for use in southeastern Brazil. Elsevier, Brazil, Solar Energy vol. 87, p. 158-167. 2013.

MARTÍN-DOMÍNGUEZ, A. et al. Efficiency in the disinfection of water for human consumption in rural communities using solar radiation. Elsevier, Mexico, Solar Energy vol. 78, p. 31-40. 2005.

MBONIMPAA, E. G. et al. Continuous-flow solar UVB disinfection reactor for drinking water. Elsevier, USA, Water Research vol. 46, p. 2344-2354. 2012.

MCGUIGAN, K. G. et al. Solar water disinfection (SODIS): A review from bench-top to roof-top. Elsevier, Journal of Hazardous Materials 235-236, p. 2946. 2012.

MCLOUGHLIN, O. A. et al. Solar disinfection of contaminated water: a comparison of three small-scale reactors. Elsevier, Solar Energy vol. 77, p. 657664. 2004.

NASPOLINI, H. F. et al. The role and benefits of solar water heating in the energy demands of low-income dwellings in Brazil. Elsevier, Brazil, Energy Conversion and Management vol. 51, p. 2835-2845. 2010.

NAVNTOFT, C. et al. UV-A (315-400 nm) irradiance from measurements at $380 \mathrm{~nm}$ 
for solar water treatment and disinfection: Comparison between model and measurements in Buenos Aires, Argentina and Almeria, Spain. Elsevier, Solar Energy vol. 83, p. 280-286. 2009.

OPPEZZO, O. J. Contribution of UVB radiation to bacterial inactivation by natural sunlight. Elsevier, Argentina, Journal of Photochemistry and Photobiology B: Biology 115, p. 58-62. 2012.

SAITOH, T. S., EL-GHETANY, H. H. A pilot solar water disinfecting system: performance analysis and testing. Elsevier, Japan, Solar Energy Vol. 72, P. 261-269. 2002. 